\title{
Introduction to the Theory of Linguistic Inventory Typology: Gaining Insights from the "Inventory"
}

\author{
Wu Jianming*, Liu Xuelei \\ Institute of Linguistics, Shanghai International Studies University, Shanghai, China
}

Email address:

wu.jianming2011@hotmail.com (Wu Jianming)

${ }^{*}$ Corresponding author

\section{To cite this article:}

Wu Jianming, Liu Xuelei. Introduction to the Theory of Linguistic Inventory Typology: Gaining Insights from the "Inventory". International Journal of Language and Linguistics. Vol. 7, No. 1, 2019, pp. 23-31. doi: 10.11648/j.ij11.20190701.14

Received: December 22, 2018; Accepted: January 10, 2019; Published: January 31, 2019

\begin{abstract}
In the light of current studies in language typology, this paper introduces one of the latest linguistic developments in China, i.e. the theory of Linguistic Inventory Typology. This theory holds that linguistic forms in a language tend to be language-particular, which constitute an inventory of their own, yet human cognition and common communication needs will lead them to unity. Some major insights from this theory, such as mighty category, cross-categorical correspondence, inventory split, in-/out-of-inventory, two-way interaction and non-independence, etc. are addressed in this paper with examples.
\end{abstract}

Keywords: Linguistic Inventory Typology, Form \& Meaning Patterns, Mighty Categories

\section{Introduction}

Since Greenberg's pioneering work on work order in 1960s [11], language typology has made great progresses. There have been more and more insights into how languages should be described, analyzed or compared. It has now become a multi-dimensional discipline, involving not just the descriptive or comparative practices, but also the studies of language contact, areality, genealogy, evolution and even correlations with social or natural factors. Above all, language typology emphasizes on empiricism, where unity is sought through the observed diversity of languages.

In this paper, the authors will introduce one of the latest linguistic developments in China, viz. the theoretical conception of Linguistic Inventory Typology (hereinafter referred to as LIT), which was originally proposed by the Chinese scholar, Liu Danqing [20, 21, 25]. LIT holds that linguistic forms in a language tend to be language-particular, yet human cognition and common communication needs will lead them to unity. Thus, in the eye of LIT, complex form-meaning patterns are expected among languages in both diachronic evolution and synchronic distribution, yet its missions are not limited to the observation of linguistic varieties but also to seek generalizations beyond the varieties. The term "inventory", as employed, suggests the very basic concern of this theory, that is, the sum of linguistic expressions at different levels of a language and across languages.

The introduction of LIT in Chinese linguistics and its application in both linguistics and applied linguistics have brought about great interest among linguists in China $[1,2,6$, $10,18,19,29,35,39,40,43,46,47,49,50,59,60,64]$. Generally speaking, every theory has its starting questions. In terms of the subject matter, the readers may want to know at least the followings: i) What motivates LIT? ii) What are the claims of LIT? iii) Are there any supporting evidence to these claims? iv) How to tackle linguistic issues with LIT? These questions are to be addressed in this paper.

\section{Motivations for LIT}

When typologists compare languages around the world, they may encounter various linguistic traditions, e.g. the Indo-European linguistic tradition, the Arabic linguistic tradition, the traditional grammar of Chinese or Japanese, etc. It is almost certain that linguistic terms from any one of these traditions do not have direct correspondence with each other. A typical case in point is the term "split words" in Chinese. Split words are typically disyllable words, yet the two words can be separated by inserting additional elements between them. In the following examples, words in the left column are known as split words, in contrast to their split counterparts in the right column, as in (1). 


$\begin{array}{ll}\text { a. } & \text { shuì jiào "sleep" } \\ \text { b. } & \text { shuì jiào "sleep" } \\ \text { c. } & \text { zhuā jín "clutch" } \\ \text { d. } & \text { jìng lì "salute" } \\ \text { e. } & \text { xǐ zăo "bath" } \\ \text { f. } & \text { chuĩ niú "boast" }\end{array}$

We see that the inserted elements can be the aspect marker le (1a), the numeral $y \bar{\imath}$ "one" (1b), the negative marker $b \dot{u}_{\text {not }}$ "not" (1c), the classifier gè (1d), the combination of "numeral + classifier + noun modifier", $y \bar{y}_{\text {one }} g \grave{e}_{C L F} r \grave{e}_{\text {hot }}$ shuú $\check{u}_{\text {water }}(1 \mathrm{e})$ or even the interrogative word, shén- me "what". Since words in the left column are detachable, Chinese scholars gave them a name, "phrasal words" (see [31]), because they are "phrases when separated and words when combined" [59]. The term "split words" or "phrasal words" thus captures the very essential property of the above words and is useful for the purpose of studying or learning Chinese. In view of this, they are indeed descriptive category in the sense of Haspelmath [14], which is viewed as language-particular and exists for the sole purpose of describing a language in their own way (e.g. economically). In contrast, typologists need comparative concept [14], which are in essence a set of varied cross-linguistic properties that intend for cross-linguistic comparison only. Not surprisingly, some linguists argue that "split words" in Chinese are nothing but "cognate object constructions" just like those in English, as in sleep a sound sleep [34], or at least resemble the "light verb + object constructions", as in have a sleep [28]. However, as far as this paper is concerned, we should be aware that, despite the seemingly similarities, there are differences. The category of split words had better be considered in the context of Chinese grammar, that is, how words or phrases are defined in this language, including syllables per word, prosodic patterns, morpho-syntactic rules as well as semantic \& pragmatic meanings. In view of this, Siewierska et al [41] rightly point out that the notion of split words in Chinese does pose a challenge to current morpho-syntactic theories in typology.

There are, of course, more examples like this. The absence of English-like articles in Chinese is another case in point. In the English sentence, a panda eats bamboos, the indefinite article $a$ indicates a type of generic reference for the head noun panda; if translated literally, this sentence will be (2a), but more appropriate translation is $(2 b)$ :

$$
\begin{aligned}
& \text { a } y \bar{\imath} \text { zhī xióngmāo chī zhúž̀ } \\
& \text { one CLF panda eat bamboo } \\
& \text { "There is a panda eating bamboos." } \\
& \text { b xióngmā chī zhúzì } \\
& \text { panda eat bamboo } \\
& \text { "Pandas eat bamboos." }
\end{aligned}
$$

Since Chinese lacks English-like indefinite articles, English $a$ roughly corresponds to $y \bar{l} z h \bar{l}$ "one + classifier" in Chinese. However, this translation is problematic because it engenders a proposition, there is a panda eating bamboo (at the moment) (2a), where panda is a referential one in the Chinese context. shui $_{\text {sleep }} l e_{A S P}$ jiào nap "have slept"

shui sleep $y \bar{t}_{\text {one }}$ jiào nap $_{\text {nave }}$ "have sleep"

$z h u \bar{a}_{\text {hold }} b \dot{u}_{n o t} j i n_{\text {tight }}$ "cannot hold(it) tightly"

jìng salute $g \grave{e}_{C L F} l_{\grave{l}_{\text {salute }}}$ "give a salute"

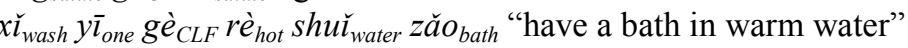

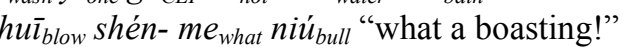

The correct translation has to be (2b), where the bare noun xióngmāo "panda(s)" is used because Chinese typically uses this type of nouns for generic/indefinite reference. This is regarded by LIT as an instance of how language may differ in content with regards to their own available means of expressions (see section 3.4 below).

The above linguistic phenomena remind us that there are at least two factors underlying language typology: i) unity $v s$. diversity: languages may have unified/similar features, yet they are somehow different; ii) presence vs. absence: one language may possess certain types of linguistic means, whereas another language lacks them. Therefore, language typology is not a practice that ignores terms or categories originated from individual languages; nor should it prioritize any particular language and takes it to be norms for others. In recent years, the concept of being "framework-neutral" has been widely accepted in typology $[8,14]$. To wit, when typologists conduct language comparison, especially in the coding of properties, they should not take some pre-established categories for granted. On the contrary, they should be able to observe the very basic linguistic phenomena with a free or neutral mind so that valid generalizations or new discovery can be made. Being framework-neutral is a good way to avoid biases or at least reminds us of the existence of such biases. For example, Nichols [33] proposes a simple yet widely accepted typology, namely, head-marking vs. dependent-marking. It is found that, although head-marking is dominant among the world's languages, current linguistic theories, nevertheless, focus extensively on dependent-marking languages, which happen to be the main feature of Indo-European languages. In other words, it is necessary to be framework-neutral when encountering different types of languages.

In the similar vein, LIT also adopts the concept of being "framework-neutral" and builds its methodology on it. The term "inventory" suggests that it targets at those observable linguistic forms, as well as at how these forms may interact with meanings. In particular, it focuses on how forms may, in turn, affect the expression of meaning. Hence, "inventory", in a broad sense, refers to the sum of linguistic expressions at different levels of a language, including sounds, lexemes, morphology, syntax, etc. [20]; in a narrow sense, it refers to formal expressions that center around one core meaning/function, e.g. person, number, gender, etc. With these backgrounds in mind, we then proceed to the next section introducing the major insights from LIT.

1 The term "framework-neutral" is adopted from Nichols [33]. 


\section{Major Insights from LIT}

In this section, some basic concepts from LIT will be introduced, including "mighty category", "cross-categorical correspondence", "split in inventory", "in/out of inventory", etc $^{2}$. These concepts are not pre-established grammatical categories or prescriptive rules, rather they are generalized facts based on the observed linguistic phenomena. They are intended to be tools for language studies.

\subsection{Mighty Category}

One of the core concepts with LIT is "mighty category". According to Liu [21], mighty categories are a type of linguistic expressions that are highly grammaticalized, syntactically powerful and associated with core meanings; in addition, they tend to have semantic expansion and can be applied analogically; they are also frequently used, highly obligatory and readily activated in the mind. As we can see, mighty categories, if pinpointed, are fundamental to the grammatical scenario of a language.

Liu [20] points out that the term "mighty" has been inspired by the notion of "prominence" [37], but it is also different from "prominence" or some related concepts, such as "priority", "salience" or "unmarkedness", because it emphasizes on the mightiness of certain linguistic means that affects the expression of meanings in a language. This is how this concept differs from others. After discussing these issues with Mr. Liu, the authors suggest that mighty categories should at least have the following properties:

Firstly, mighty categories are distinct typological features that are deeply rooted in a language or groups of languages. Let's take Chinese morphology for example. It is well-known that Chinese is an analytical language and the majority of monosyllable morphemes can be used as an independent word, viz. a high morpheme to word ratio, as in (3):

$\begin{array}{llllll}\text { (3) } y \grave{u} & \text { bú } & \text { zhuó } & \text { bú } & \text { chéng } & \text { qì } \\ \text { jade } & \text { not } & \text { polish } & \text { not } & \text { become } & \text { ware } \\ \text { rén } & \text { bú } & \text { xué } & \text { bú } & \text { zhì } & \text { dào } \\ \text { man } & \text { not } & \text { study } & \text { not } & \text { know } & \text { way }\end{array}$

"If a piece of jade is not polished, it cannot become a good ware; if a man does not study, he cannot know the way of life."

Analyticity is therefore a distinct typological feature for Chinese and it certainly affects a series of consequences for this language. As we can see, in contrast to stress-timed languages (e.g. English), Chinese is a syllable-timed language, that is, each syllable takes approximately the same amount of time to be pronounced. In current Mandarin Chinese, there are a lot of disyllable words, which, nevertheless, form a stable tonal pattern. For example, Wang \& Cao [44] point out that "in different moods, two-syllable words maintain stable tonal patterns"; Ye [58] points out that "the basic prosodic patterns in Mandarin Chinese is high-low, i.e. trochee". These are considered "mighty" features for Chinese because they are

\footnotetext{
${ }^{2}$ See [47] for a detailed discussion of LIT in Chinese.
}

fundamental to the grammar of Chinese.

Secondly, mighty categories are prevailing form \& meaning patterns in a language at certain periods in the language history. To illustrate, let's look at the typology of word order. It is known that the typical word order in ancient Chinese is (S)VO, and only under the following three syntactic environments can $\mathrm{OV}$ be possible, namely, i) an interrogative pronoun is pre-posed, ii) a pronominal object is pre-posed in a negative sentence, and iii) in certain focus constructions, as in (4a-b) (quoted from [24]):

$\begin{array}{cllllll}\text { (4) a } & \text { 吾 } & \text { 谁 } & \text { 欺 } & \text { 欺 } & \text { 天 } & \text { 乎 } \\ & w u & \text { shui } q \bar{\imath} & q \bar{\imath} & \text { tiān } & h \bar{u} \\ & \text { I } \quad \text { who bully } & \text { bully } & \text { god } & \text { Particle } \\ & \text { "Who I have bullied? The god?" }\end{array}$
b. 今楚师 至 晋不我救 jīn chǔ shī zhì jìn bú wǒ Jiù now Chu troops arrive Jin not I save "The troops of Chu kingdom have arrived, and Jin kingdom is not going to save us."

$\begin{array}{llllllll}\text { c. 率 } & \text { 师 } & \text { 以 } & \text { 来 } & \text { 唯 } & \text { 敌 } & \text { 是 } & \text { 求 } \\ \text { shuài } & s h \grave{\imath} & y \grave{l} & \text { lái } & \text { wéi } & d i & \text { shì } & \text { qiú } \\ & & & & & \text { ene } & \text { is } & \text { seek }\end{array}$

"Since (I) took command of the army, the only thing I have done is to seek the enemy (for battles)."

However, if SVO is the dominant word order for ancient Chinese, it is not necessarily the case for modern Chinese, which is known for its mixed word orders, namely, co-existence of $\mathrm{VO}$ and $\mathrm{OV}$ order. This is largely due to the rise and prevalence of topic and disposal constructions in Modern Chinese. As we can see below, the topic construction (5a) moves the post-verbal objects to the sentence-initial position, and there is no need to fill in the moved object position with a pronominal; the disposal construction( $(5 \mathrm{~b})$ also moves the object from the post-verbal position to the preverbal one (not necessarily the sentence-initial position). With the spread of these two constructions, OV order has become more acceptable nowadays than it was before.

$$
\begin{aligned}
& \text { a. } y u ́ \text { wǒ măi le. } \\
& \text { fish }_{\text {TOP I }} \text { buy ASP } \\
& \text { "I bought fish." } \\
& \text { b. ní kuài bă fàn gěi wǒ. } \\
& \text { you quickly } \mathrm{BA}_{\text {disposal }} \text { food give me } \\
& \text { "Give me the food quickly." }
\end{aligned}
$$

From the perspective of LIT, Chinese topic and disposal constructions are mighty categories (though to different extent). Their "might" not only resides in their frequency of usage but also in their ability to bring about changes in word order. Such changes, nevertheless, are diachronic in nature and are only observable over time.

Thirdly, mighty categories tend to have semantic expansions and even affect the other functional categories in 
the inventory. Take Chinese topic constructions again for example. As we know, topic constructions can be divided into two parts, viz. topic and comment. There are a number of elements that can fill in the topic position, e.g. nominals, verbal phrases, complements, etc. These topics do not require a dedicated grammatical marker (but by no means reject them, e.g. particles like 啊 $\bar{a}$, 吧 $b a$, 吗 $m a$, 嘛 $m a ́)$. Noticeably, topic constructions can also be part of a complex modifying structure, overriding the known clausal patterns [51-52]. For example,

\begin{tabular}{|c|c|c|c|c|c|c|c|c|c|}
\hline wǒ & $\begin{array}{l}\text { rèn wéi } \\
\text { think }\end{array}$ & $\begin{array}{l}z h e ̀ \\
\text { this }\end{array}$ & $\begin{array}{l}\text { běn } \\
\text { CLF }\end{array}$ & $\begin{array}{l}s h \bar{u} \\
\text { book }_{\mathrm{TOP}}\end{array}$ & $\begin{array}{l}d \dot{u} \\
\text { read }\end{array}$ & $\begin{array}{l}\text { guò } \\
\text { ASP }\end{array}$ & $\begin{array}{l}d e \\
\text { MOD }\end{array}$ & $\begin{array}{l}\text { rén } \\
\text { person }\end{array}$ & $\begin{array}{l}b \grave{u} \\
\text { not }\end{array}$ \\
\hline
\end{tabular}

More importantly, topic constructions can incorporate such meanings as passivity (7), possession (8) or comparison (9), yet they are typically expressed with dedicated grammatical constructions in other languages [22].
$n \grave{a}$
that

\section{běn}
CLF
$\operatorname{sh} \bar{u}$
book $_{\mathrm{TOP}}$
wǒ men
we
Lit. "The book got lost by us carelessly."

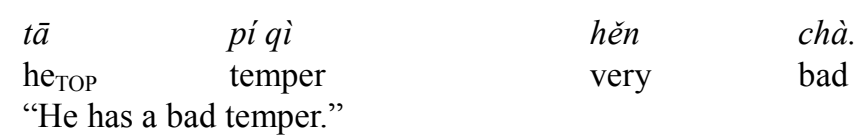

$\begin{array}{llll}\text { băi huò } & \text { dà lóu } & \text { jià gé } & \text { b̌̀ } \\ \text { grocery } & \text { building } & \text { prop } & \text { COM } \\ \text { "(The price at the) grocery building is lower than yours." }\end{array}$

bù xiăo xīn carelessly

chà.

ad

$\begin{array}{lll}b \check{\imath} & \text { ňmen } & d \bar{\imath} \\ \text { COM } & \text { you } & \text { low }\end{array}$

Since Chinese topic constructions are frequently used, multifunctional and highly inclusive in current Mandarin, they are considered mighty by LIT.

Fourthly, mighty categories are highly accessible and easily activated in the mind. This is an area of study related to psychology or cognitive science. And it calls for more empirical proofs with experiments. In terms of mightiness of topic constructions, for example, recent experiments in psycholinguistics show that topics are cognitively more salient than subjects in language production and comprehension and topics are more likely to be antecedents of pronominal anaphora than subjects $[54,55,57]$.

Of course, mighty categories are not limited to topic constructions in Chinese, and should exist at the level in a language, e.g. phonology, morphology, syntax, semantics or pragmatics. Such a concept is necessarily useful because it pinpoints those key factors in cross-linguistic comparison, which actually helps us understand some highly-controversial issues, such as "comparability" in languages.

\subsection{Cross-Categorical Correspondence}

"Cross-categorical correspondence" [25] is also related to the concept of mighty category, which means that there is an indirect correspondence between categories among languages. More specifically, it means that a language-particular category (especially the mighty one) may be associated with a set of meanings or functions, yet these meanings or functions may be expressed by or subsumed under a different category in another language. Thus, cross-categorical correspondence reveals a universal tendency that categories between languages are not equally matched. For LIT, this phenomenon is at least caused by the diachronic processes of language change, where functional expansion or contraction are widely-seen. For example, in the proto Indo-European languages, reflexivity (that is, an agent acts upon himself/herself) did not have a dedicated formal expression; instead, it was co-expressed by the middle markers (i.e. the subject being affected by an event). Later a dedicated reflexive form emerged in some of the languages and expanded its functions so as to incorporate the middle meanings. The rise of reflexive markers, however, prompted the disappearance of middle markers in most Indo-European languages. As a consequence, for Romance (such as Spanish, Italian, etc.), reflexivity is a grammatical category that includes impersonals, middles and passives, while for Celtic (such as Welsh, Irish, etc.), reflexivity is distinguished from the middles with separate forms. Therefore, the term "reflexives" in current Indo-European languages does not refer to the same semantic/functional domain and has to be considered within their own inventory.

Thus, cross-categorical correspondence between languages actually reflects how form \& meaning patterns are unevenly distributed among the world's languages. This is exactly what has interested typologists recently. As we know, contemporary typology has, in the main, shifted its concerns from exploring the possible (e.g. implicational universals: postposition $\supset \mathrm{GN}$ ) [11] to the probable [3-4] (e.g. tendencies or statistic universals). As has been pointed out by Bickel [3], current typological researches can be summarized as "what, where, why", in which "what" refers to what structures exist in human language, "where" refers to which areas tend to have these structures and "why" refers to why these structures appear in these areas.

From the perspective of LIT, population, geography, society, history and many other factors also contribute to the uneven distribution of linguistic forms. This can be seen as variations 
in the linguistic inventory around the world, where mighty categories play an essential role.

\subsection{Inventory Split \& In-/Out-of-Inventory}

"Inventory split" and "in/out of inventory" are two related concepts. The former means that, when a linguistic form changes its semantic focus or its formal realization and is no longer considered by the native speaker to be a member of the existing category, it is viewed as a sign of "inventory split" [26]. To illustrate, let's look at verbal reduplication in Mandarin Chinese. Diachronic researches show that verbal reduplications

$$
\begin{array}{lll}
\text { a. verbal-quantifier/object: } & \begin{array}{l}
d \check{a} \\
\text { hit } \\
\text { "hit once" }
\end{array} \\
\text { b. verbal reduplications: } & \begin{array}{l}
\text { dă dă } \\
\text { "hit hit" }
\end{array} \\
\text { c. adjectival reduplications: } & \begin{array}{l}
\text { yuán yuán } \\
\text { "round round" }
\end{array}
\end{array}
$$

From the view of Chinese linguists, verbal reduplications have broken away from verbal-quantifier/object constructions, and native speakers no longer regard them as belonging to the same category. In this case, it is an instance of "inventory split". In this regard, LIT will look into the mechanism of inventory splitting as well as necessary morpho-syntactic criteria for this splitting.

$\begin{array}{llll}\text { 请 } & \text { 损 } & \text { 之, } & \text { 月 } \\ \text { qŭng } & \text { sǔn } & z h \grave{l} & y u e ̀ ~ \\ \text { let(me) } & \text { reduce } & \text { it } & \text { monthly } \\ \text { 来 } & \text { 年 } & \text { 然 } & \text { 后 } \\ \text { lái } & \text { nián } & \text { rán } & \text { hòu } \\ \text { next } & \text { year } & \text { then } & \end{array}$

"Please let me reduce the number and steal one chicken every month. So I can stop stealing next year." (from The Mencius Teng Wengong)

With the emergence of classifiers in Chinese, they became increasingly obligatory in noun phrases, i.e. in the structure of "numeral + classifier + nouns". Modern Chinese is now a classifier language, where classifiers are obligatory and mighty, in the sense that they incorporate a set of functions, such as classification, individualization, quantification, deixis, etc. From a diachronic point of view, classifiers are a new member in the grammatical inventory of Chinese (i.e. the inventory of part-of-speech) and this is viewed as a phenomenon of "in-inventory" (see [24] for details). On the contrary, ancient Chinese distinguishes verbal semantics by means of voicing alternation (i.e. voiceless vs. voiced consonants ), e.g. 见 jiàn/xiàn “see/appear" 败 bài "defeat/lose", yet such means have disappeared in Middle Chinese $[15,32]$, and this is considered to be a case of "out-of-inventory".

According to LIT, a member's in or out will generally affect the other members in the same inventory. Yet, how and why changes may occur in the inventory, apart from the above mentioned classifiers, are worthy of further exploration. in Mandarin were derived from the verbal-quantifier/object constructions in ancient Chinese [9, 61]. Both of them have very similar structural and semantic properties (e.g. both can be inserted with a numeral, an aspect marker and have a meaning of short-term span, etc.). Nowadays, verbal reduplications have acquired their own prosodic and morpho-syntactic status and deviated from the original verbal-quantifier/object constructions. In fact, they are often treated as belonging to the category of reduplication (e.g. the same as the adjectival reduplication) [23]. For example.

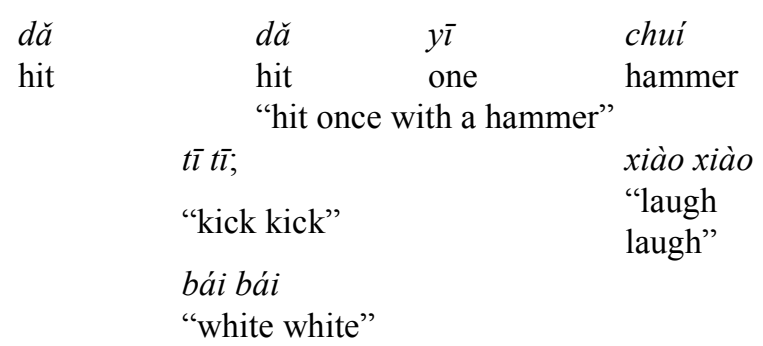

On the other hand, a new expression entering the inventory, where new patterns of form \& meaning emerge, which is then called "in-inventory". Conversely, the process of withdrawing from the existing inventory in diachrony is called "out-of-inventory". Take the category of classifiers for example. Ancient Chinese did not possess classifiers and numerals can be placed directly before a noun, as in (11):

$\begin{array}{lllll}\text { 捛 } & - & \text { 鸡, } & \text { 以 } & \text { 待 } \\ \text { răng } & y \bar{l} & j \bar{\imath} & y \check{\imath} & \text { dài } \\ \text { steal } & \text { one } & \text { chicken } & \text { PREP } & \text { wait } \\ \text { 己 } & & & & \\ y \check{l} & & & & \\ \text { stop } & & & & \end{array}$

\section{4. "Two-way Interaction" and "Non-independence"}

As has been mentioned earlier, LIT focuses primarily on the interaction between forms and meanings. To wit, a meaning is expressed through forms yet forms may, in turn, affect the meaning(s) expressed, which is called "two-way interaction". Take the case of word order for example again. As we know, location of adverbials, they are consistently placed ahead of the verb, as in "ADV +V+O" [12]. It is this fixed arrangement of constituents that may produce some mixed meanings. For example,

$$
\begin{array}{lcccl}
t \bar{a} & z \grave{j} j \check{l} & c h a \bar{i} & \text { le } & \text { xinfēng. } \\
\text { he } & \text { self } & \text { open } & \text { ASP } & \text { letter } \\
\text { "He opened the letter himself." } &
\end{array}
$$

In the above sentence, it is not easy to say whether ziji is an adnominal appositive to the subject $t a$ "he" or an adverbial marking the manner of the verb. And we may have a mixed the basic word order in Chinese is SVO, and in terms of the 
reading, i.e. focus of identity and manner of action. This is an instance how forms, i.e. the " $\mathrm{ADV}+\mathrm{V}+\mathrm{O}$ " order, affect the meanings expressed. In contrast, English have these two meanings co-expressed by the same $x$-self yet in different locations, e.g. "the president himself opened the letter" and "the president opened the letter himself". The former is called "adnominal intensifier" and the latter, "adverbial intensifier" [16].

In addition, LIT is concerned with "non-independence", which means meanings or functions are sometimes not distinctly extractable in one language than they are in another language. Importantly, non-independence is not the same as polysemy, the latter of which generally takes the view that one meaning is for one linguistic context. The above-mentioned $z i j i$ "self" and the topic constructions in (7-9) are also such cases of "non-independence", where mixed meanings can be found. From the perspective of LIT, when a mighty category increases its frequency and even usurps other semantic categories, it becomes even mightier, which, in turn, strengthens its status in the inventory.

\section{Current Researches Connected to LIT}

Ever since the introduction of LIT, it has spurred great interest among linguists in China. There are a number of studies in the field of linguistics and applied linguistics closely related to LIT. Some of them are listed below.

\subsection{In the Field of Linguistics}

In the field of linguistics, current researches involve two dimensions, i.e. diachrony and synchrony. In terms of diachronic studies, Shi [40] explores the mightiness of verb-complement directional constructions in Chinese, e.g. $z u \grave{o}_{s i t}$ xià ${ }_{\text {down }}$ "sit down", zó walk $_{\text {waut }} c h \bar{u}_{\text {out }}$ "walk out", and points out that the expansion of verb-directional constructions is a key factor underlying the change of motion events in Chinese, i.e. from being "verb-framed" to "satellite-framed". In addition, he also illustrates how the evolution of linguistic structures affects that of conceptual structures, where forms/structures have a counter effect on meanings. Besides, Gao \& Wu [10] illustrate how the verb 趟 tàng(tāng) “wade/go through" was grammaticalized into a classifier due to the mightiness of classifiers in Chinese.

At the synchronic level, Xia \& Yan [50] examine the diminutive marker 唧 $t_{6} i$ in Xiang and Gan, and argue that diminutive markers are mighty in Chinese dialects. Bai [1-2] explores cross-linguistic variation regarding the ability of the construction, "Def-NP", to express kind-reference and concludes that when the category of identifiability is mighty in a language, the construction, "Def-NP", is more likely to express kind-reference. Lu et al. [29] investigate the mighty status of verb-complement state phrases in Chinese and point out this has to do with the distinct typological feature in Chinese, where natural focus tends to be post-posed.

There are other studies that are also constructive. For example, Qiang [35] finds out that the choice of subjective markers in a language is actually influenced by the other mighty categories in the linguistic inventory. Xia [49] investigates the functional word, 阿 $a$ in Yiyang dialect, which can serve as a classifier or a definite article and suggests that mightiness may have multiple occurrences on the grammaticalization path. Lin [19] discovers that topic structures in Chinese, which enable shifts of preposition phrases to the preverbal position, while the focus structures enable shifts to the post-verbal position. $\mathrm{Wu}$ [46] carries out a survey on major Chinese dialects and finds that there are structural differences among Chinese person paradigms and since some person forms are not engaged in complementary distribution, there is a need for the concept of "inventory structure" for the description of person in Chinese [48]. Wan [43] finds out that the interrogative adverb in Chinese dialects can be used to perform many pragmatic functions, such as speculation, inquiry, confirmation, consultation, etc. and it can be used in real interrogative sentences only when it is a mighty category. $\mathrm{Yu}$ [59] points out that tense is a mighty category for English but realis/irrealis is not; in contrast, the latter is a mighty category for Chinese but the former is not. Zhou [64] finds that in many Chinese dialects, agents in passive sentences cannot be omitted, which can be explained by the notion of "two-way interaction".

The above studies are closely related to LIT, which shows that the concept of "inventory", especially mighty category, may have provided good food for thoughts in Chinese linguistics.

\subsection{In the Field of Applied Linguistics}

Applied linguistics is a field that is also known to be connected to language typology [8, 17, 36, 42, 45, 62, 63]. For example, Since the 1990s, many scholars in China have begun to explore the relationship between typology and translation [56]. In recent years, there have been many works combining these two fields, e.g. Chinese and English [38, 53], Chinese and Japanese [66], Chinese and Spanish [30] and so on. In language acquisition, Eckman [8] studies the connection of Markedness Differential Hypothesis ${ }^{3}$ and The Structural Conformity Hypothesis ${ }^{4}$ with second language acquisition. $\mathrm{Li}$ [18] combines language acquisition theory with LIT and proposes the concept of "variation space" (i.e. the specific variation range of variant forms). It is found that mighty forms in the learner's mother language and target language are more likely to appear in the inter-language. Importantly, it is found that second language acquisition begins with an understanding of "form" and then enters into a stage of form \& meaning matches. Also in translation, Dai [6], based on large-scale corpus statistics, found that in the continuum of "left-dislocation topic structure - argument-like topic genitive topic - time /place/background topic", the left side is

\footnotetext{
3 The hypothesis believes that typological markedness reflects the difficulty in second language acquisition. It predicts that the marked structure is more difficult to learn than the corresponding unmarked one. The difficulty is consistent with the relative markedness of the structure [8].

4 The hypothesis believes that the cross-linguistic universals that exist in the primary language also exist in the inter-language [8].
} 
more likely to be translated into a topic structure in English, while the right side usually resorts to other means for translation in English.

The above-mentioned studies in applied linguistics, including many others not mentioned here, are quite encouraging for LIT. Nevertheless, more efforts and collaboration are called for in the future studies, especially in the fields of language teaching, machine translation, multilingual lexicography, etc.

\section{Conclusion}

As a mature discipline, contemporary language typology has developed from the traditional practice of language classification to more and more diverse research orientations. The theory of Linguistic Inventory Typology is one of them. Nevertheless, this theory is still in its developmental stage. In order to be a fully-grown theory, more issues need to be clarified, studied and explored, such as how to identify items in an inventory, extraction of properties for inter-language comparison, operational criteria for mighty categories, degree of mightiness, psycho-linguistic or neuro-linguistic evidence, etc. Despite all these, LIT is a promising theory for typology and the authors are looking forward to its new findings and applications.

\section{References}

[1] Bai G. (2013) A Cross-Linguistic Investigation into the Generic Reference, Graduate School of Chinese Academy of Social Sciences.

[2] Bai G. (2015) Definite Markers in the Expression of Kind-Reference: in the Framework of Linguistic Inventory Typology, Journal of Foreign Languages, 4, pp 21-36.

[3] Bickel, B. (2007) Typology in the 21st Century: Major Current Developments. Linguistic Typology 11, pp 239-251.

[4] Bickel, B. (2015) Distributional Typology: Statistical Inquiries into the Dynamics of Linguistic Diversity. In Bernd Heine \& Heiko Narrog, Eds, The Oxford Handbook of Linguistic Analysis. 2nd edition. Oxford: Oxford University Press.

[5] Croft, M. (2001) Radical Construction Grammar: Syntactic Theory in Typological Perspective. Oxford: Oxford University Press.

[6] Dai R. (2016) The Application of Linguistic Inventory Typology in Translation Theory and Practice, Graduate School of Chinese Academy of Social Sciences.

[7] Dixon, R.M.W. (2010) Basic Linguistic Theory. Vol. 1. Oxford: Oxford University Press.

[8] Eckman Fred R. (2011) Linguistic Typology and Second Language Acquisition. In Song (ed.) The Oxford Handbook of Linguistic Typology. Oxford: Oxford University Press.

[9] Fan F. L. (1964) On "Verbal Reduplication", Studies of the Chinese Language.

[10] Gao Y. N., Wu Ch. A. (2014) The Grammaticalization of
Quantifier "Tang" in Chinese from the Perspective of Mighty Category Expansion, Research in Ancient Chinese Language, 2, pp 41-46.

[11] Greenberg, Joseph H. (1963) Some Universals of Grammar with Particular Reference to the Order of Meaningful Elements. In Joseph H. Greenberg (ed.) Universals of Human Language, 73-113. Cambridge, Mass: MIT Press.

[12] Guo Zh. (2013) A Typological Investigation on the Place between OV/VO Word Order and Adverbial Phrase, Minority Languages of China, 1, pp 46-57.

[13] Haspelmath, M. (2007) Pre-Established Categories Don't Exist - Consequences for Language Description and Typology. Linguistic Typology 11, pp 119-132.

[14] Haspelmath, M. (2010) Comparative Concepts and Descriptive Categories in Crosslinguistic Studies. Language 3, pp 663-687.

[15] Hong B., Yang Z. L. (2010) The Initial Voicing Alternation and its Origin in Pre-Qin Chinese Jian-Type Verbs, Minority Languages of China, pp 22-28.

[16] König, E., \& V. Gast (2006) Focused Assertion of Identity: A typology of intensifiers. Linguistic Typology 2, pp 223-276.

[17] Li J. M., Wu F. Y. (2013) Typological Generalizations and Chinese Relative Clauses Produced by Second Language Learners, Foreign Language Teaching and Research, 1, pp $80-92+161$.

[18] Li Y. (2014) On the Variability of the Second Language Acquisition of Chinese Ditransitive Constructions, Chinese Teaching In The World, 01, pp 80-92+161.

[19] Lin Zh. (2013) A Pragmatic Study on the Shifting of Chinese Preposition Phrase, Journal of Graduate School of Chinese Academy of Social Sciences, 4, pp 114-119.

[20] Liu D. Q. (2011) Linguistic Inventory Typology: a Proposal for a New Approach of Linguistic Typology, Contemporary Linguistics, 4, pp 289-303.

[21] Liu D. Q. (2012a) Some Mighty Categories in Chinese: a Perspective of Linguistic Inventory Typology, Chinese Teaching in the World, 3, pp 291-305.

[22] Liu D. Q. (2012b) The Homogeneity of Comparison and Topic Structure in Chinese: an Illustration of the Expansive Power of Mighty Categories, Studies in Language and Linguistics, 4, pp $1-12$.

[23] Liu D. Q. (2012c) Primary and Secondary Reduplications: Multiple Diachronic Sources of Reduplicative Forms, Dialect, 1 , pp 1-11.

[24] Liu D. Q. (2013) The Syntactic Development from Ancient Chinese to Modern Chinese: An Inventory Typology Perspective in Cross Dialects. In the Fourth International Sinology Conferennce. Linguistic Information and Typology.Taibei: Academia Sinica.

[25] Liu D. Q. (2014) On the Maximum Utilization Principle of Language Inventory, Studies of the Chinese Language, 5, pp $387-401+479$.

[26] Liu D. Q. (2015a) Split in Linguistic Inventory: The grammatical variation in Sound and Meaning of "Xu" in $\mathrm{Wu}$ Dialect. Essays on Linguistics 1, Beijing: The Commercial Press. 
[27] Liu D. Q. (2015b, January) The Form and Meaning in Linguistic Inventory Typology. Paper presented at the Conference on Celebration of 10th Anniversary of China and Japan Theoretical Linguistics Association Establishment, Japan, Doshisha University.

[28] Lu B. F., Xie T. W. (2002) On Broadening the Scope of Grammatical Comparison between Chinese and English, Journal of the Chinese Language Teachers Association, 1, pp 111-130.

[29] Lu B. F., Ying X. F., Zhang G. H. (2015) On the Mighty Category Status of the Complement of State in Chinese Grammar, Studies of the Chinese Language, 3, pp 195-205+287.

[30] Lu J. Sh. (2016, Sept.) The Reflexives in Spanish and Comparison with English and Chinese, In the First Symposium in Cross-Linguistic Research- Cross-Linguistic Form of Reflexives and Intensifiers Inventory Symposium. Shanghai International Studies University.

[31] Lv Sh. X. (1979) Grammar Analysis in Chinese, Beijing: The Commercial Press.

[32] Mei Z. L. (1991) The Development of Verb-Complement Structure in Chinese from "dong (move), sha (kill)" and "dong (move), si (die)" in Han Dynasty and Comment on the Word Neutralization of Agent and Patient in Mid-ancient Chinese. Essays on Linguistics 16, Beijing: The Commercial Press.

[33] Nichols, J. (2007) What, If Anything, is Typology? Linguistic Typology 11, pp 231-238.

[34] Pan H. H., Ye K. (2015) Separable Words and Cognate Objects in Mandarin Chinese, Contemporary Linguistics, 3, pp 304-319+376-377.

[35] Qiang X. N. (2011) The Past Subjunctive Mood Marker manhao (蛮好) in the Shanghai Dialect, Studies of the Chinese Language, 2, pp 155-163+192.

[36] Ramat, A. G. ed. (2003) Typology and Second Language Acquisition. Berlin: Mouton de Gruyter.

[37] Sasse, H. -J. (1995) Prominence Typology. In J. Jacobs, A. S. von Stechow, W. Sternefeld \& T. Vennemann, (eds) Syntax: An International Handbook of Contemporary Research. Vol. 2. Berlin / New York: Walter de Gruyter. pp 1065-75.

[38] Shang X. (2014) The Tense and Aspect Type and Translation Strategy in Chinese and English, Shanghai: Shanghai Century Publishing.

[39] Sheng Y. M. (2016, Sept.) Linguistic Inventory Typology and Argumental Intensified Pronouns, In the First Symposium in Cross-Linguistic Research- Cross-Linguistic Form of Reflexives and Intensifiers Inventory Symposium. Shanghai International Studies University.

[40] Shi W. L. (2014) The Diachronic Expansion and Effect of Linguistic Inventory Mightiness-the Development of Verb-Direction Structure, International Journal of Chinese Linguistics, 2, pp 293-324.

[41] Siewierska, A., Xu J., \& Xiao Z. (2010) Bang-le yi ge da mang (offered a big helping hand): A Corpus Study of the Splittable Compounds in Spoken and Written Chinese. Language Sciences 1, pp 464-487.

[42] Sun W. F. (2012) Language Typology and Second Language
Acquisition, Language Teaching and Linguistic Studies, 2, pp $1-8$.

[43] Wan Q. (2014) Pragmatic Functions of Interrogative Adverb, Chinese Language Learning, 2, pp 11-19.

[44] Wang R., Cao W. (2009) Experimental Study of Disyllabic Sentences in Standard Chinese, Journal of Tsinghua University (Science and Technology), S1, pp 1316-1317+1319-1321+1327.

[45] Wang Y, Zhou Y. F. (2014) Second Language Acquisition and Linguistic Typology, Foreign Languages in China, 5, pp 49-55.

[46] Wu J. M. (2013) Sinitic Perspectives on the Paradigmatic Structure of Person Marking[J]. Contemporary Linguistics, 4, pp 393-404.

[47] Wu J. M. (2018) Frontiers in linguistic typology: Gaining insights from the "Inventory". Language Teaching and Linguistic Studies, 2018,2, pp70-80.

[48] Wu J. M. (2018) Language Typology and Grammars towards New Descriptivism: Description on the Inventory of ziji and its Structure, Contemporary Linguistics, 4, pp 525-536.

[49] Xia L. P. (2013) On the Multifunction of "a 45 " in the Yiyang Dialect, Hu'nan Province, Studies of the Chinese Language, 1, pp 64-76+96.

[50] Xia L. P., Yan Y. Q. (2015) On the Subjectification and Morphological Change of Diminutive Marker [tci] (唧) in Xiang and Gan Dialects: a Case of Yiyang Dialect, Hunan province Dialect, 3, pp 262-273.

[51] Xu, L. \& D. T. Langendoen, (1985) Topic Structures in Chinese. Language 1, pp 1-27.

[52] Xu L. J., Liu D. Q. (1998/2007) The Structure and Function of Topic, Shanghai: Shanghai Educational Publishing.

[53] Xu W. Sh. (2015) A Linguistic Typology Approach to Contrastive Analysis and Translation of English-Chinese Conjunctions: an ECCC Case Study, Journal of Foreign Languages, 3, pp 41-52.

[54] Xu X., Zhou X. (2015) Topic Shift Impairs Pronoun Resolution During Sentence Comprehension: Evidence from Event-Related Potentials. Psychophysiology, 53(2), 129-142.

[55] Xu X. D., Ni Ch. Bi., Chen L. J. (2013) The Influence of Topic Structure and Verb-Based Implicit Causality on Pronoun Resolution in Mandarin Chinese: Evidence from Sentence Production and Comprehension, Modern Foreign Languages, 4, pp 331-339+437.

[56] Xu Y. L. (1987) The Language Type Distinction and Translation, Journal of Foreign Languages, 3, pp 56-61.

[57] Yang, X., X. Chen, S. Chen, X. Xu, \& Y. Yang (2013) Topic Structure Affects Semantic Integration: Evidence from Event-related Potentials. PloS one, 8(12), DOI: 10.1371/journal.pone.0079734.

[58] Ye J. (2014) The Phonetic Study of Chinese Rhythemical Words, Jilin Normal University Journal(Humanities \& Social Science Edition), 2, pp 36-43.

[59] Yu X. J. (2016) The Mightiness and Expansion of (ir)realis Category in Chinese: From a Perspective of Prototype Categorization across Languages, Foreign Language Teaching and Research, 5, pp 680-692+800. 
[60] Yu X. J. (2017) Categorization, Mightiness and Expansion of Tense-Aspect-Modality across Languages: A Perspective from Linguistic Inventory Typology, Studies of the Chinese Language, 6, pp 670-692+767.

[61] Zhang Ch. (2000) The Origin of "V-V" and "VV" in Modern Chinese, Language Teaching and Linguistic Studies, 4, pp 10-17.

[62] Zhang Ch. (2016) An Exploration into Typological Study of Second Language Acquisition in Grammar, Journal of Yantai University (Philosophy and Social Science Edition), 2, pp 114-120.

[63] Zheng Zh. G. (2014) The Typological Markedness Hypothesis and Interlanguage Phonology Acquisition, Language Teaching and Linguistic Studies, 6, pp 29-36.
[64] Zhou Ch. L. (2016) On the Restriction of Form to Meaning from the Perspective of Agent in Passive in Chinese Dialects, Studies in Language and Linguistics, 1, pp 59-66.

[65] Zhu D. X. (1982) Grammar Handout, Beijing: The Commercial Press.

[66] Zhu F. (2013) A Contrast Study of Zero Anaphora in Chinese and Japanese Texts and an Application to the Paragraph Translation between Chinese and Japanese, Journal of Japanese Language Study and Research, 1, pp 21-127. 